\title{
Algunas sagas comerciales francesas en el Madrid de la segunda mitad del seiscientos *
}

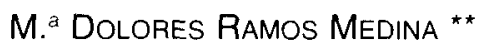

\section{RESUMEN ABSTRACT}

El objetivo de este articulo es analizar la evolución de algunas sagas comerciales francesas del comercio de ropas y tejidos de Madrid entre 1659 y 1673. Estas sagas comerciales siguieron una

trayectoria ascendente cuyo resultado fue un complejo entramado de alianzas gracias a la concertación de algunos matrimonios de conveniencias dentro de la comunidad mercantil francesa asi como otros calcularon sus acuerdos entre la comunidad mercantil minorista incorporada al comercio de los tejidos y el abastecimiento de Madrid.
The aim of this article is to analyze the evolution of some French merchant families between 1659th and 1673rd in Madrid. They organized some marrieges of conveniences and these merchants follewed a trajectory which was the result of a network of alliances. Some french merchants allied to others families installed in Madrid at the first half of the 17th century because of their business interests. And, finnally, they developed their agreements and the result was a sucessful economic and social integration within the flourishing retailer merchant community in Madrid.

* Este trabajo forma parte del Proyecto de Investigación DGICYT PB 96-0097.

** UNED. 


\section{INTRODUCCIÓN. FUENTES Y METODOLOGIA PARA EL ESTUDIO DE LA BURGUESIA MERCANTIL FRANCESA EN MADRID}

El estudio de la burguesía mercantil francesa, que resulta uno de los colectivos de extranjeros más numeroso que se establece en la Península a lo largo de la época moderna ', constituye una de las mayores lagunas que hoy en día tiene planteada la historiografía madrileña ${ }^{2}$. En la base de ello se encuentra un problema de escasez de documentación directa - archivos privados de los comerciantes-y se puede afirmar que son los protocolos notariales las fuentes sustitutivas adecuadas ${ }^{3}$, reveladoras de la evolución de las estructuras de la actividad económica y de la proyección social ${ }^{4}$ de las diversas generaciones burguesas, como algunos estudios reinvindicaron en los años cincuenta ${ }^{5}$.

No obstante, su utilización entraña una meticulosa labor, no exenta de dificultades. Por una parte, el mayor obstáculo se encuentra en el elevado índice de movilidad de la comunidad mercantil extranjera en la época moderna ${ }^{6}$; y por otra, la utilización de estos fondos custodiados en los Archivos de Protocolos en el área de lo que fue la Corona de Castilla para el análisis de la historia de los comerciantes, como sus agentes económicos, resulta laboriosa debido a la inexistencia de catalogación originaria; es decir, la ordenación

ALCOUFFE, D., "Contribution a la connoissance des émigrés français de Madrid au XVII" siècle", Melanges de la Casa Velázquez, 2, (1966), págs. 179-197; Giralt y Raventos, E., "La colonia francesa de Barcelona a mediados del siglo XVIin. Estudios de Historia Moderna, Barcelona, VI (1960), págs, 215-278; VILlar Garcia, B., Los extranjeros en Málaga en el siglo xvim, Córdoba, 1982. VV.AA., Les Français en Espagne à l'epoque moderne (xvi-xvi $\left.\right|^{e}$ ), Paris, 1990.

Aportaciones sobre la burguesía mercantil madrileña. Ver: Bravo LozANo, J., "Don Francisco de Horcasitas. Las posibilidades de Madrid a finales del siglo Xvil». Estudios de Historia Social, 36-37, Madrid, (1986), págs.497-522; "La emigración a Madrid", en MADRazO, S., y PINTO, V., Madrid en la época moderna: Espacio, sociedad y cultura, Madrid, 1991; y, por último, en "Redes familiares burguesas", La burguesia española en la España Moderna, Valladolid, 1997, vol. III, págs. 1397-1408; Alvar Ezouerra, A., "Mercaderes en Madrid (1540-1640), Primeras notas", La burguesia española en la Edad Moderna, ENCISO RECIO, L.M. (ed.), vol. III, 1991, págs. 1439-1457.

Estudios especificos sobre la burguesia mercantil extranjera en la época moderna a través de la documentación notarial: FRANCH BENAVENT, R., "Las dinastías comerciales genovesas en la Valencia del siglo xvil: Los Causa, Batífora y Ferrano". Actas del II Coloquio de Metodología Histórica Aplicada, Santiago de Compostela, 1984, 2, págs. 296 y ss.; en esa misma publicación las aportaciones de J. Montemayor sobre los genoveses en Toledo: (...) Actas del II.C.M.H.A., vol. 1, y en "Quelques affaires génoises á Toledo au Xvle siécle». Melanges (1982), págs. 287-293, 291. Franch Benavent, R., El capital comercial valenciano en el siglo XvII, Valencia, 1986, págs. 21-31.

Fefnandez Diaz, R., «Protocolos notariales y el estudio de la burguesia barcelonesa del siglo xvill', Estudis Historics i Documents dels Arxius Procols (1980), VIll, págs. 253-274; pág. 254. VICENS VIVES, J., “La historia a través de las protocolos notariales", Obra dispersa, págs. 386-388. Se trata de un artículo publicado en su dia en Destino, 106, 12 de febrero de 1949.

- Destacaban que sólo tras un exhaustiva revisión de registros parroquiales, matrículas de hospitales, fuentes fiscales y recuentos oficiales consiguen subsanarse. 
del material por cada uno de los diferentes notarios madrileños que atiende a una tradición castellana que desde el siglo XVI suprimía el antiguo sistema de notas literales (utilizado solamente, en algunos casos, para los testamentos), y que disponía de un registro ordenado cronológicamente ${ }^{7}$. Allí, de forma general y sin criterio alguno, se iban anotando todo tipo de negocios. Así que la documentación consultada cuenta con una secuencia anual sin clasificación documental previa, que ofrece un sinfín de documentos de todo tipo mezclados en cada uno de los libros de protocolos conservados anualmente por cada escribano. No sucede lo mismo en la Corona de Aragón donde, herederos de una tradición bajomedieval ${ }^{8}$, los mismos notarios organizaban sus protocolos de testamentos e inventarios con mayor racionalidad, lo que indudablemente agiliza hoy la labor del investigador. Esta situación provoca que a lo largo del tiempo se almacenen en algunos núcleos urbanos, especialmente en algunos tan importantes como Sevilla o Madrid, miles de protocolos sin catalogación alguna, lo que hoy en día dificulta, en gran medida, la labor del historiador. Quizás sea esta la razón (entre otras muchas) del respeto que provoca tal documentación a los investigadores, que temen introducirse en esa selva documental que representan los archivos notariales, y que no haya alcanzado todavía el desarrollo que cabría esperar por la riqueza que encierran ${ }^{9}$. No obstante, como "bolsas de silencios de la sociedad" (según las denomina el profesor Eiras Roel) y también de la economía (añadimos nosotros), las escrituras notariales ofrecen una interesante información, a modo de instantáneas, sobre la vida familiar y el entorno cotidiano del mercader en las sociedades preindustriales. Sin embargo, se trata de un trabajo bastante arduo por la mencionada falta de ordenación que llega a desalentar al investigador. Hay que añadir, por último, que Madrid cuenta para los años analizados con una nómina de escribanias superior a las doscientos setenta en una de las centurias, sobre todo en la segunda mitad del Seiscientos ${ }^{10}$, con un mayor número de minutas notariales.

A.H.P.M., Indice cronológico de escribanos y protocolos, Tomo I, 1540-1750, Madrid, 1981. (Inédito)

8 Bono Huerta, J., Los archivos notariales, Sevilla, 1985, pág. 23; Lopez Salazar Perez, J., "Los protocolos notariales. Fuentes documentales para la historia moderna", La investigación y las fuentes documentales de los archivos. Guadalajara, 1996, págs. 43-45.

9 Eiras Roel, A., "El protocolo notarial en la historia urbana". Historia y documentación notarial. El Madrid del Siglo de Oro. Jornadas celebradas en Madrid, 2 a 4 de junio de 1992, Madrid, 1992, págs. 47-78. GOMEZ ZORRAQUiNO, J.L., "Los problemas de la documentación notarial como fuente histórica en los siglos XV1 y XVII", El patrimonio documental aragonés y la historia. Zaragoza, 1982, págs. 122-123; y en El notario español (1962), 54, págs. 111-128.

10 Destacada en: VAzQUez de Prada, V., "Protocolos notariales e historia económica: crédito, comercio e industria", Actas del II Coloquio de Metodología Histórica Aplicada. La documentación notarial y la historia, II, págs. 189-218, pág. 191. 
Nuestra información por tanto en este terreno viene condicionada por el azar, que ha preservado los datos de algunas sagas comerciales, mientras que no permite obtener noticias sobre otras. Un trabajo sistemático de vaciado de un buen número de escribanías madrileñas del siglo XVII que conservan documentos de este segmento mercantil, lo que exigió una gran paciencia, además de un perfecto conocimiento de la naturaleza de estas fuentes y de sus posibilidades, nos proporcionó datos sobre algunas de aquellas familias francesas dedicadas al comercio de la ropa usada y los tejidos.

En cualquier caso, el método seguido sobre las sagas comerciales que protagonizan este análisis es la combinación de lo ya expuesto en otros trabajos: consiste en realizar, en palabras del profesor Eiras Roel, un seguimiento en vertical, esto es a lo largo de un período de tiempo, de todas las escrituras localizadas referentes a dichas familias. Pero, además, el seguimiento en horizontal resulta también efectivo en tanto en cuanto abarca a todos y cada uno de los documentos escriturados relativos a los agentes económicos extranjeros de un año determinado o de varios años sobre un asunto concreto de estas familias. El cotejo desde ambas perspectivas de una misma documentación constituye la aportación íntegra a la minuta notarial que persigue la visión global, aminorando así los inconvenientes y silencios de una fuente inevitablemente irregular en su producción y que por la perspectiva planteada, la atalaya familiar de un grupo reducido de mercaderes, iría contra la propia naturaleza de la documentación notarial: el análisis de series de datos. Por tanto, una perspectiva global en las dos direcciones anunciadas daría un rango superior a la documentación utilizada para el acercamiento a la realidad cotidiana de las familias mercantiles ${ }^{11}$.

En cuanto a la tipología documental ${ }^{12}$ empleada en el presente trabajo, su elección ha dependido del azar, y nos ha proporcionado una desigual representatividad - y en algunas ocasiones sentida ausencia- de escrituras notariales. Los testamentos localizados, que constituyen una prueba valiosa para el conocimiento de las últimas voluntades de estos mercaderes, aportan una información básica. Por una parte, sobre las relaciones familiares, se nos informa de la procedencia y genealogía en primer grado (padres, mujer

1 Elras RoEl, A., "El procolo notarial en la historia urbana”, Historia y documentación notarial..., pág. 52 .

${ }_{12}$ Remitimos al análisis del profesor EIRAS ROEL, A., "Tipología documental de los protocolos gallegos", La Historia social de Galicia en sus fuentes de protocolos, Madrid, 1980. FERNÁnDEZ, R., «Los protocolos notariales y el estudio de la burguesía barcelonesa..., págs. 258 y ss. Una clasificación de tono juíídico: BONO HUERTA, J., "Conceptos fundamentales de la diplomática notarial", Historia, Instituciones y Documentos, 19 (1992), págs. 73-88. 
e hijos) del testador, lo que supone un importante adelanto en la averiguación de cuáles fueron los lazos familiares con los que sus miembros se unieron al resto de la comunidad y la medida de su contribución a la reproducción endogámica de este grupo, entroncando así con el tema de la movilidad social. Del mismo modo, mediante la mención expresa que en estos documentos se hace de los albaceas testamentarios podemos acercarnos $-\mathrm{y}$ así lo hemos intentado- al conocimiento de las amistades del testador, cuyo resultado, en el caso de estas familias del comercio de ropa y tejidos, nos proporciona las conexiones económico-sociales que unen a unos y a otros, de tal forma que avanza algunos datos significativos que tendrán una proyección en las alianzas económicas en las que la familia se encuentra inscrita. Por otra parte, los testamentos permiten analizar el papel de esta modesta burguesía madrileña en su formación socio-profesional, como son los mercaderes de lonja franceses.

En este análisis, al objeto clásico de utilizar los contratos matrimoniales como medio de aproximación para el análisis de este grupo social tan reducido y modesto se unen conocidas limitaciones tales como la existencia de un único régimen matrimonial en la legislación castellana, por lo que la gran mayoría de la población no solía registrar en un contrato notarial sus aportaciones al matrimonio. Del mismo modo, los inventarios «post mortem" no han podido consultarse con la representatividad adecuada, a pesar del vaciado completo de casi un centenar de escribanías que durante estos años contienen información sobre las diferentes generaciones mercantiles francesas que se dan cita en el Madrid del Seiscientos debido a que nos encontramos en los niveles más modestos del comercio francés.

Con todo, nuestro objetivo es el análisis de aquellos elementos fundamentales en la actuación de los agentes económicos en las sociedades preindustriales, el parentesco y la adscripción a un grupo social determinado ${ }^{13}$, en ese intento de analizar las bases económicas de la actuación de un segmento del colectivo mercantil galo en Madrid en la segunda mitad del siglo XVII. Aunque, si bien es cierto que en el ámbito madrileño es aún difícil responder a cuestiones fundamentales como las relacionadas con las características de la estructura familiar del comerciante, el estudio que presentamos de la familia francesa, aunque con un grado de información desigual, relaciona este primer agente de socialización con el matrimonio.

13 Como nos recordaba: MaIXE ALTES, J.C., "Parentesco y relaciones sociales en el seno de la burguesia barcelonesa. Los extranjeros en la Barcelona de los siglos XVII y XVIII", Revista d'Historia Moderna, Manuscrits, 6 (1987), págs. 151-175. Los estudios de Lespagnol, A., Messieur de Saint Malo. Une élite negociante au temps de Louis XIV, Rennes, 1997, 1 , pág. 91. 
La familia ${ }^{14}$ del comerciante francés es la institución a través de la cual se lleva a cabo no sólo la reproducción de todo su sistema social ${ }^{15}$, sino también la posibilidad de reproducción económica ${ }^{16}$-recordemos que se convertía en un órgano de consumo y acumulación de capital comercial susceptible de ser transmitido ${ }^{17}$-. Además, hay que tener en cuenta, como indicaba Francisco Chacón, que las relaciones de parentesco, la constitución de alianzas matrimoniales y - añadimos nosotros - un espacio aglutinador, definidor y a la vez diferenciador de la unidad familiar y, sobre todo, de su realidad sociológica ${ }^{18}$ dirigido por el "pater familias", son algunos de los factores que condicionan y a su vez se ven condicionados por las directrices de este último.

Por último, se trata de una burguesía mercantil que actúa en dos niveles de actuación distintos. En este sentido, la estructura de las relaciones sociales que vamos a definir a continuación se mantendrá en las décadas siguientes, básicamente en el seno de la colonia francesa, a la par que algunas familias francesas de aquella pequeña burguesia en ascenso, que protagoniza buena parte de este análisis desarrolla nuevas relaciones con el conjunto de la sociedad madrileña. Este aspecto es básico para comprender una institución que tiende a la individualización pero que en sí misma crea una fuerza centrífuga que la comunica con la sociedad en la

1.4 La familia ha sido en las últimas década objeto de una creciente atención por los historiodores. Analizada con renovado bagaje metodológico desde un enfoque multidisciplinar su estudio cuenta con abundante bibliografía de la que destacamos las aportaciones de CHACON JIMÉNEZ, Fco. "La familia en España: una historia por hacer", en La familia en la España Mediterránea (siglos $x(y-x(x)$. Barcelona, 1987, pág. 14. También en "La historia de la familia desde la perspectiva de la historia social», CASTillo, S. (Coord.), La historia social en España. Actualidad y perspectivas, Madrid, 1991,págs. 261-66. En la historiografía francesa: BUTEL, P., “Comportaments familiaux dans le négoce Bordalais au XVIIle siècle», Annales du Midi, 88, 127 (1976), págs. 139157; págs. 144 y ss. Otras aportaciones sobre la comunidad mercantil en diferentes espacios geográficos pero que no abordan su conexión con la actividad económica en un estudio integral son: Fernandez Perez, P., cMujeres y burguesía en el Cádiz del siglo XVill», págs. 281-298; ToRRES SANCHEZ, R., "El hogar del burgués", vol. I, págs. 35-46 y, por último, IMIzCOZ BEUNZA, J.M." y Ángulo Morales, A., "Burguesia y redes de relaciones en la sociedad del Antiguo Régimen", en Enciso Recio, L.M. (Ed.) La burguesia española..., vol. I, págs. 253-268. Por último, el libro de reciente publicación que aborda las estrategias familiares de la burguesía gaditana en el siglo xvIH: Fernandez PEREZ, P., El rostro familiar de la metrópoli, Madrid, 1997.

is VILAR, P., La Catalogne dans L'Espagne Moderne, Paris, 1962, III, págs. 384 y ss. Destacaba la perspectiva familiar de los negocios de casas como los Alegre. Esta línea sería seguida por los análisis de las bases de la burguesia catalana que bajo la dirección del profesor $\mathrm{C}$. Martínez Shaw, como una profundización de su estudio Cataluña en la Carrera de Indias, realizara $R$ Fernández en su análisis de la familia Gloria.

16 Chacón, Fco., “La tamilia en España...”, pág. 14.

17 FERNANDEZ, R., "La burguesía barcelonesa en el siglo XVIII: La familia Gloria "La economía española al final del Antiguo Régimen", Madrid, 1982, II, págs. 31-97.

is Chacon, Fco., "La familia en España...", pág. 26. 
que se inserta, la sociedad madrileña del siglo XVII en los niveles comerciales dominados por la burguesía comercial de origen extranjero estrechando el círculo en los niveles de la negociación dejando al margen las familias españolas. Por ello, parece oportuno explicar los mecanismos y las estrategias ${ }^{19}$ que se plantean en el interior de cada grupo familiar constatando así la importancia que tendría el capital comercial en la mayor o menor movilidad de esta burguesía tradicional ${ }^{20}$.

\section{LOS MERCADERES DE ROPA FRANCESES. UNA CUESTIÓN DE PARENTESCO Y DE ADSCRIPCIÓN NACIONAL}

En efecto, en los niveles más modestos de la comercialización francesa como es el comercio de ropas - también denominados "fripiers" franceses $^{21}$-, que oscilaba entre la venta y el alquiler de trajes para fiestas y comedias tan popularizadas en la Corte ${ }^{22}$, destacan en particular tres familias de mercaderes los Mateo, los Cocot y los Astorgue cuyas noticias de su asentamiento en Madrid se remontan a la primera mitad del siglo XVII. Podemos decir que en 1659 presentan un entramado interesante de relaciones de parentesco que manifiesta un peso específico propio, tanto en el contexto de la colonia como en sus relaciones con la sociedad madrileña. De hecho, la documentación notarial deja traslucir un abigarrado conjunto de estos comerciantes que se encuentran intimamente relacionados a través del matrimonio con la actividad económica de la familia -ya que es un poco pronto para hablar de casa comercial en estos niveles tan modestos de la comercialización- a la que pertenecen, pero también el círculo de amistades en torno al núcleo nacional es importante para su incorporación a la comunidad madrileña. El carácter endogámico de sus matrimonios realizados dentro del grupo nacional -es también el caso de otras familias como los Vergara y Trebolet de cierta relevancia

19 Como por ejemplo en el caso de la burguesía valenciana una centuria después: FrANCH BENAVENT, R., "Las relaciones matrimoniales de la burguesía mercantil valenciana dieciochesca", La burguesía española..., II, págs. 783-794.

20 Para una definición de este concepto: Cir. Martinez Shaw, C., "La sociedad urbana en la Cataluña del siglo XVIII", Manuscrits. Revista d'historia moderna, 11 (1993), pág. 117.

MOLAS, P. La burguesia mercantil en la España del Antiguo Régimen, Madrid, 1985, pág. 73.

22 A.H.P.M. P. ${ }^{\circ} 9768$, fols. $30-30 \mathrm{v}, 22$ de febrero de 1661 , se firma un contrato de alquiler entre la viuda de Juan Astorgue que lleva el negocio familiar, con su libro de cuenta y razón, asi como de caxa ( $P .^{\circ} 7252,1664$, fols. 304-304v.). Estos profesionales eventuales del alquiler de vestido y calzado para fiestas junto a sastres, pasamaneros y zapateros comparten un espacio comercial con aquellos otros ofici tales como los alquiladores de hatos de principios de la centuria: Ver GARCIA GaRcia, B.J., "El alquilador de hatos Luis de Monzón y el negocio teatral madrileño a comienzos del Seiscientos", La burguesia española..., III, págs. 695-709; pág. 702. 
económica entre los roperos de viejo franceses de Madrid ${ }^{23}$ - refuerza su posición económica en este ramo del comercio al detall, como demostraremos a continuación. No obstante, sus relaciones sociales se desarrollarán en un contexto social y profesional muy determinado y de nacionalidad: el de la Cofradia y Hospital de San Luis de los Franceses ${ }^{24}$ lo que provocó, en un primer momento, que sus relaciones con la sociedad madrileña no fueran relevantes. En este sentido, se trata de dos elementos de referencia que identifican al individuo francés con un grupo nacional ${ }^{25}$. Además, como lugar preferente de sociabilidad esta institución facilitará el desarrollo de vecindades entre los franceses de la ciudad donde confluyen y se concretan multiformes redes de solidaridad nacional, también económicas ${ }^{26}$. En este encuentro en ámbitos concretos de la nación se facilita el contacto con el microcosmos en que se desarrollan sus negocios.

\section{Los Mateo se asientan en Madrid}

Los Mateo eran oriundos del obispado de Clermont (Auvergne), y estaban establecidos desde principios de siglo en las localidades de Brosenque en la parroquia de Trisac, de donde procedia Giraldo. Era hijo de Lucas Mateo y Agueda Laurisecha y es el primer ropero de la familia que se establece en Madrid, aunque desconocemos la fecha exacta de su llegada. Asimismo, desconocemos las causas inmediatas de la emigración de los Mateo. No sabemos hasta qué punto los problemas económicos

\footnotetext{
23 Familias como los Vergara y los Trebolet, tradicionaimente roperos de viejo, trazan lazos de parentesco entre ellos: A.H.P.M:, P17252, 21 de abril de 1664 y fols. 192-192v. Testamento de Antonio de Vergara que tiene su tienda en régimen de alquiler en la calle de la Sal.

24 El 31 de julio de 1622 se pedia la confirmación de los estatutos de la cofradia en un Memorial de don Enrique de Saureulx, administrador de dicha institución benéfica: A.H.N., Cons. Leg. 7141, 31 de julio de 1622. Dos años después se confirmaban los estatutos de estas dos cofradías: la de San Luis y la de Nuestra Sra del Buen Fin de españoles y criados de S.M., ambas adscritas al Hospital de San Luis de los Franceses: A.H.N., Cons., leg. 7137, exp. 17; también en PInflo, L., Anales de Madrió (desde el año 447 al de 1658), I.E.M., 1971, pág. 27 ; AlCoUfFE, «Emigrés français de Madrid", Melanges, 1966, II, pág. 180. Ya en la segunda mitad del siglo XVII esta institución benéfico asistencial tiene una gran importancia: A.H.N., Cons, Leg. 7178, exp. 31 Instrucciones del Administrador del Hospital de San Luis de esta Corte que realizaba la petición de no ser molestado por las represalias contra franceses y se les permita tener despensa abierta como a los demás hospitales de la corte para el sustento de los enfermos. Por último, a finales de siglo se recoge la petición del Rey de que no lleguen al Hospital de San Luis de la capital más franceses: B.L. Add., 21.537, fols. 307-312.

25 Redondo, A., (Ed.), Les parentes fictives en Espagne (xvie-xvir siècles), Publications de la Sorbonne, Paris, 1988, pág. 39.

${ }_{26}$ Es el caso de Juan Astorgue, el menor, que vertebra en su actuación la comunidad mercantil de los roperos adscritos a la cofradia pues presta a Juan Constan, un mercader ropero y cofrade de San Luis.
} 
Algunas sagas comerciales francesas en el Madrid de la segunda mitad...

por los que atraviesa esta región francesa superpoblada, pudieron forzar su salida. La familia materna pertenecia a uno de los apellidos franceses del pequeño comercio ambulante establecidos en Madrid ${ }^{27}$ desde principios del siglo XVII. Los Laurisecha habian conseguido alcanzar un alto grado de integración social en 1637. De hecho, Guillermo Laurisecha, que pertenecía a la cofradia del Convento de San Felipe, donde sería sepultado, destaca por su integración en el seno de la comunidad mercantil madrileña como un extranjero más que se había naturalizado, escalando posiciones no sólo económicas sino también sociales, pudiéndose, incluso, equiparar su nivel de integración al de un mercader de lonja lorenés en la segunda mitad del siglo XVII.

Giraldo, que condiciona las directrices de la casa en Madrid hasta 1659 en calidad de "pater familias", se desposó sin que sepamos la fecha exacta con María del Bosque Miranda. Ésta había nacido en Madrid en los años treinta y era hija de Pedro de Miranda, un comerciante agremiado casado con Ana Rodríguez, un matrimonio que ocupaba un lugar acomodado y gozaba de un prestigio reconocido entre la burguesía mercantil madrileña dedicada al comercio de ropa usada. La familia Mateo tenía su establecimiento en la callejuela de la Sal, en las proximidades de la calle de las Postas, uno de los centros comerciales de la burguesía mercantil madrileña y su capital era modesto, según declaraba en $1659^{28}$. Tras el fallecimiento de Giraldo, su esposa contraería segundas nupcias con Antonio Mateo, su cuñado ${ }^{29}$ - hijo de Lucas pero de su primer matrimonio con Maria Chacha (De la Acha?. Ver árbol genealógico). No hemos localizado los contratos dotales de estos matrimonios y las noticias que nos proporcionan información son muy escasas sobre las aportaciones que realiza el marido al matrimonio, por lo que - no conociendo su valor real- podemos advertir que es la endogamia social, e incluso profesional y los matrimonios entre iguales, las características que definen las sagas comerciales que analizamos a continuación. En cualquier caso, según Franch Benavent ${ }^{30}$, la propia naturaleza del contrato dotal - si lo hubiere-, se limita a recoger la dote de la

\footnotetext{
${ }^{27}$ Oriunda de Montirat, un lugar del obispado de Clermont, era hija de Pedro Laurisecha y de Ana Bisier, dos apellidos frecuentes entre las familias que controlan el comercio ambulante francés en Madrid.

28 A.H.P.M., P. 7248 , fols. 283-283v., y en 295-295v.: "Testamento de Giraldo Mateo", 11 de noviembre de 1659 .

29 En general, los burgueses mantuvieron relaciones multiformes, algo que ya ha sido destacado repetidas veces: Imizcoz Beunza, J.M. ${ }^{2}$ y Angulo Morales, A., "Burguesía y redes de relaciones...", pág. 45.

30 Franch Benavent, R., "Las relaciones matrimoniales de la burguesía mercantil valenciana dieciochesca," La burguesía española..., II, pág. 791.
} 
mujer y las arras que le otorga el marido, omitiendo en la mayoría de los casos cualquier referencia a los bienes que posee éste o que le entregan sus padres con ocasión del matrimonio.

En este sentido, la solución es remitirnos a los casos de otros roperos coetáneos a los Mateo (Ver nómina I) y casados con españolas - como Giraldo- aunque de origen francés. En efecto, el matrimonio de Pedro de la Fuente, ropero de viejo francés, con María del Prado, natural de Madrid ${ }^{31}$, nos ofrece el valor de la dote aportada que asciende a 2.641 reales de vellón -aunque en ella se incluya la legítima del padre- y podría aproximarnos a la cuantía de aquellos mercaderes roperos como Giraldo, esto es, los hijos de aquéllos ${ }^{32}$ que dejaron sus lugares de nacimiento y se trasladaron a Madrid en busca de mejoras en su medio de vida. No obstante, María del Bosque ordenaba inventariar la hacienda final de su difunto marido Giraldo Mateo que ascendió a 13.977 reales de vellón ${ }^{33}$ más unos 4.400 reales de vellón en deudas de su negocio ${ }^{34}$.

Por tanto, las redes de relaciones establecidas a través de vínculos matrimoniales aseguran la estabilidad de estas modestísimas familias comerciales y facilita a sus miembros la extensión y el crecimiento de los negocios ${ }^{35}$. No obstante, existen estrategias propiamente económicas, destinadas a asegurar la repioducción del patrimonio que, a su vez, suponen una inversión social, directa o indirectamente orientada a la instauración y el mantenimiento de relaciones sociales de «clase». Por otra parte, la constitución de matrimonios de este tipo no sólo demuestra la fuerza de la autoridad del "pater familias" y la sumisión a las exigencias del negocio sino también nos recuerda que el matrimonio es una institución eminentemente conservadora que busca afianzar los entramados mercantiles de las modestas empresas galas en la ciudad. Asimismo, tal estrategia tiende de manera consciente o inconsciente no tanto a conser-

31 Sin embargo, María del Prado era hija de Juan del Prado y Maria Hernández. Su madre contraía segundas nupcias en 1659 con otro ropero francés Juan Terrada, cofrade Nuestra Señora del Buen Fin, como lo había sido Juan del Prado.

32 Nos referimos tanto a la primera generación de los Mateos, es decir, a Lucas y Ana, padres de Giraldo como a los padres de Pedro de la Fuente, es decir, a Diego de la Fuente y Margarita Moller, hija asimismo de un ropero de viejo de Chagerac en el obispado de Clermont, así como Juan de la Fuente, padre de Diego que estaba casado con la francesa Juana Robert, ambos del obispado de Clermont.

33 A.H.P.M., P. ${ }^{\circ} 7259$, fols. $368-372$.

34 A.H.P.M., P. ${ }^{\circ} 8366$, fols. $189-190,18$ de agosto de 1660 . Inventario y tasación de Antonio Mateo que entrega 4.400 reales, es decir, 45 doblones al padre de Maria del Bosque por una deuda que habia contraido Giraldo con su suegro.

35 Butel, $P_{\text {, }}$ "Comportements familiaux dans le negoce bordelais au XVille siècle", Annales du Midi, 88, (1976), pág. 139-157; pág. 139. 
var o a aumentar su patrimonio sino que, en mayor medida, mantiene e, incluso, mejora su posición en las relaciones dentro del grupo nacional.

En efecto, los parientes de unas y otras familias formaban una pléyade de pequeños mercaderes especializados en el comercio minorista francés (árboles genealógicos) y adscritos a la cofradía francesa (Ver nómina) lo que les permite reproducir sus estructuras económicas y sociales en los niveles modestos de la negociación en los que incluiremos al mayoritario colectivo de mercaderes ambulantes franceses - caxeros- adscritos a esta misma institución benéfico asistencial, que no sólo quiere decir —en las sociedades preindustriales - mantenerse sino también ascender. La familia Mateo, por ejemplo, podría considerarse una de aquellas familias modestas cuyos capitales oscilan entre 1.300 reales y 5.000 reales de vellón lo que equivale al capital invertido por un mercader ambulante francés en una «caxa» de mercancías para la venta por las calles y plazas de la villas y lugares de Castilla. La incorporación de una dote al capital inicial de cualquiera de estos mercaderes les permite contar con una mayor capitalización para protagonizar una progresiva integración tanto económica como social en las estructuras de la Villa y Corte. Además, para la familia Mateo - como para otros roperos- su integración social comienza con los matrimonios con hijas de mercaderes conocidos de origen francés, pues ascender puede ser la forma de mantenerse en su posición preferente ante la colonia y la cofradía.

\section{Los Astorgue}

Establecidos los términos de permanencia de quienes -como los Mateo- constituyen los niveles elementales del comercio de ropas capitalizados por mercaderes franceses cuyo primer paso para la integración, en la mayoría de los casos, ha sido el matrimonio con española, comienza la disolución del contenido nacional de la colonia francesa ${ }^{36}$. En una segunda fase, los matrimonios que estrechan lazos con la pequeña burguesía madrileña persiguen dotar a los vástagos de un capital intermedio que les permita ascender. En este estadio de la integración se encuentra la segunda familia seleccionada: los Astorgue.

Con el análisis de esta familia, por una parte, observamos cómo en la segunda generación de roperos franceses la endogamia nacional desaparece,

36 Franch Benavent, R., El capital comercial valenciano..., pág. 222, habla de matrimonios entre extranjeros del mismo origen nacional e idéntico medio social. Pero se puede perfilar si se profundiza en el grupo nacional concreto como ha resultado del análisis de la colonia mercantil francesa en Madrid que presentamos en este estudio. 
un fenómeno común al resto de los inmigrantes de esa nacionalidad, pues como ha comprobado $\mathrm{Cl}$. Larquie a partir de los registros de matrimonios de la parroquia de San Ginés, la mayoría de los franceses - setenta y dos casos de un total de ochenta y siete- enlaza con mujeres españolas, siendo sólo seis quienes lo hacen con francesas y nueve con mujeres de otras nacionalidades ${ }^{37}$.

Por otra parte, con los Astorgue podemos hablar con propiedad de actitudes profesionales y del concepto de casa - como en cierta medida hemos hecho con los Mateo- en torno a la figura del "pater familias". Además, en 1659 la familia Astorgue toma el relevo al frente de la mayordomia de la cofradía.

Los Astorgue, que hunden sus raices en la ciudad de Madrid desde principios de siglo, comparten una procedencia común con el resto de roperos de viejo franceses, pues mayoritariamente proceden de diferentes villas y lugares del obispado de Clermont en Auvergne. El creador de la dinastía, Juan Astorgue, el "pater familias" de la empresa ${ }^{38}$ hasta 1668 , era natural de Cartagonda en la parroquia de Castel Marllarque, en el obispado de Clermont - Auvergne- - De padres franceses ${ }^{39}$, la tienda de este mercader se encontraba en la calle del Peso Real ${ }^{40}$ cuando contrae matrimonio con una vecina de Madrid: Jerónima Crespa ${ }^{41}$ que pertenecía a una familia del comercio de ropas de la corte. Su hermano Juan Astorgue "el menor" se casaba el 7 de abril de 1671 con Catalina Chofa que recibía una dote que ascendía a 4.000 reales en alhajas, ropa blanca y vestidos, además de dinero y otros bienes ${ }^{42}$. De este matrimonio nace Lorenza Astorgue que contraerá matrimonio con Pedro Dumas, otro ropero de viejo francés con tienda abierta en la calle de la Sal en pleno barrio de Santa Cruz.

Por último, a pesar de que estas familias se mantienen en los niveles intermedios del comercio de Madrid, se aprecia diferentes categorías

\footnotetext{
37 VV.AA. Les français en Espagne à l'èpoque moderne ( $\left.X V^{\ell}-X V I I l^{e}\right)$, París, 1990, págs. 100101.

38 De hecho se denomina Juan Astorgue "el mayor»: A.H.P.M., P. ${ }^{\circ} 9762$, fols. 241-242v., 9 de noviembre de 1668, que vive a la subida de la Red de San Luis en 1668. Enterrado en el Convento de la Victoria de Madrid, 500 misas. Una familia extensa con seis hijos: Juan Astorgue, "el mozo", Sebastiana, Angela, que se casa con un librero y, por último, tres hijos: Francisco, Pedro y Manuel.

39 Guillermo Astorgue y Juana Puyol, que permanecerian en la localidad de donde procedia esta saga comercial del comercio minorista, junto a otros familiares y amigos.

40 A.G.S., C.S., Leg. 149, 8 de enero de 1674, embargo de ropas de todo género.

41 Desconocemos la fecha de su matrimonio pues sólo nos ha llegado el poder para testar que Juan Astorgue otorga a su mujer el 16 de marzo de 1663: A.H.P.M., P. ${ }^{\circ} 7251$, fols. 201-202v.

42 A.H.P.M., P. ${ }^{\circ}$ 9768, fols. 139 y ss. En este acto Juan Astorgue, "el mayor", reconoce como dote de Catalina Chofa los 7.300 reales de vellón.
} 
Algunas sagas comerciales francesas en el Madrid de la segunda mitad...

profesionales de semejante nivel adquisitivo entre los diferentes componentes del grupo aunque no contemos con suficientes datos numéricos al efecto, las noticias reflejadas en los diferentes testamentos otorgados por miembros de la familia nos permite observar como algunos de sus miembros - tales como Antonio Astorgue, un oficial de tahona- ejercen otros oficios de menor consideración económica y por tanto social. Sin embargo, permite extender las redes familiares por diferentes ramas del abastecimiento de Madrid donde otros miembros pueden encontrar financiación económicas en momentos de apuros personales (Ver apéndice documental). Los hermanos que residen en la corte son Juan Astorgue y Antonio Astorgue, "el mayor", que ejerce de oficial de panadería y le habia financiado en un primer momento hasta con treinta $y$ cinco doblones ${ }^{43}$. Por otra parte, esta rama de la familia Astorgue no se encuentra plenamente incorporada a la estructura social de la ciudad, pues Margarita Martel, mujer de Antonio Astorgue ${ }^{44}$, permanece en este período en Francia.

Serán algunos vástagos de las generaciones sucesivas los que afiancen su situación socioeconómica en el seno de las estructuras de la Corte (ver árboles genealógicos). En efecto, Angela Astorgue contrajo matrimonio con Manuel Alonso Meléndez, un librero de Madrid, que había estado casado en primeras nupcias con doña María Sáez de la Rosa, natural de Madrid. Este nuevo matrimonio comenzaba su actividad profesional con un capital considerable que permitía hablar de una ascensión económica a la vez que social en la tercera generación de roperos. La aportación de 26.416 reales de vellón en libros se incrementaba con otros 10.631 reales de vellón ${ }^{45}$. En realidad, la integración social y económica de la familia Astorgue se habia incrementado con el paso del tiempo y la tercera generación gozaba de capital y prestigio suficiente para emprender la aventura del comercio al "detall" de más consideración, equiparándose a los mercaderes de los tejidos.

Por otra parte, los matrimonios de la hija de Juan Astorgue «el menor», que ostentan la naturaleza por nacimiento, con el hijo de un mercader ropero francés mantiene la endogamia matrimonial establecida por los roperos dentro del grupo nacional que comienza a buscar alianzas económicas en el círculo de mercaderes tenderos especializados en otros ramos de la comercialización minorista, pero con los que comparten nacionalidad y se encuen-

A.H.P.M., P. 7248 , fols. $235-236 \mathrm{v}$.

14 A.H.P.M., P. ${ }^{\circ} 7248$, fols. $171-172 \mathrm{v}$.

45 A.H.P.M., P. ${ }^{\circ} 9768$, fols. 6 de abril de 1671. El valor del capital intermedio ascendió a 35.947 reales que entregaba en este acto a Arigela Astorgue. 
tran afincados en la corte desde principios de siglo. En efecto, en círculos situados en niveles concéntricos, han de ser considerados atentamente pues, pese a su carácter cada vez más reducido y privativo, no por ello dejan de tener importancia a la hora de entender el contexto social de estos modestos roperos, aguadores y oficiales (pasteleros y de tahona).

\section{Los Cocot, una familia de roperos de viejo de Limosin}

Por último, no todas las familias de roperos que llegan a Madrid proceden de Clermont; otras como la familia Cocot, proceden del obispado de Limoges (Limousin), siendo la única familia de roperos franceses localizada de ese área de procedencia. Entre los integrantes de esta familia existen diferentes niveles socioprofesionales. Jaime Cocot, natural de la parroquia de Serendon en el obispado de Limoges (Limousin), cuenta entre sus bienes con 3.830 reales/vn y a los que sumariamos 66 ducados ${ }^{46}$ - unos 726 reales de vellón-posiblemente perteneciente a la dote de su esposa o a la legitima de sus padres, ascendiendo a un total de 4.556 reales de vellón; Antonio Cocot, hermano del anterior, tiene un capital más modesto pues tan sólo asciende a 1.812 reales de vellón ${ }^{47}$.

En 1663, Maria Dumas, hija de Pedro Dumas ${ }^{48}$-ropero de viejo francés casado con una natural de estos reinos, Isabel Gamarra-, viuda de Antonio Cocot, contrae matrimonio con Juan Cocot, hermano de su difunto marido y con un similar capital ${ }^{49}$. En este sentido, tienen en el parentesco y la adscripción nacional el fundamento de su permanencia y en las estrategias matrimoniales dentro del grupo nacional la coherencia a las numerosas actuaciones que estos agentes económicos tienen en los diferentes ámbitos del trato. En realidad, pertenece a una familia plenamente incorporada al barrio comercial de Santa Cruz, pues la tienda de Jaime y Juan Cocot ${ }^{50}$ se encuentra en la esquina de la calle de las Postas junto a una zapatería de viejo y próxima a la de la Sal, sede del gremio de roperos de viejo franceses ${ }^{51} \mathrm{El}$ régimen de alquiler del local —siendo la percha y el guardapolvo de

46 A.H.P.M., P. ${ }^{\circ} 7248$, sin foliar, 26 de marzo de 1659.

47 A.H.P.M., P. ${ }^{\circ} 7251,18$ de noviembre de 1662. Casado con María Dumas, hija de otro mercader ropero Pedro Dumas, casado a su vez con Isabel Gamarra y madre de Maria.

48 A.H.P.M., P. ${ }^{\circ} 9168$, fols. $322-322 v .$, y 324.

49 A.H.P.M., P. ${ }^{\circ} 7252,1663$, fols. 321-322v.

5n A.H.P.M., P. ${ }^{\circ} 7250$, fol. $74-74 \mathrm{v}, 13$ de marzo de 1662.

51 A.G.S., C.S., Leg. 149, 6 de noviembre de 1673, según los inventarios de bienes represaliados por el alcalde de casa y corte don Martín Joseph de Badarán. De esta situación finalmente serian dados por libres tras las comprobaciones pertinentes sobre su naturalización. 
su propiedad - habla de las modestas haciendas con que contaba esta burguesía tradicional. Además, el testamento de Juan Cocot nos permite confirmar sus redes de financiación, es decir, el gremio de taberneros, pasteleros, tahoneros y panaderos ${ }^{52}$ que reside en Madrid.

\section{LAS RELACIONES SOCIALES EN EL SENO DE LA BURGUESIAA MERCANTIL FRANCESA}

A mediados del siglo XVII la documentación consultada nos destacaba la actuación de otras familias de comerciantes de origen francés en Madrid mediante las que seguimos un proceso de encumbramiento económico y social, cuyas estrategias aunque se desarrollan entre un colectivo con cierto grado de adscripción nacional, sin embargo, se imponen fundamentos sociales en un mismo nivel socioeconómico y a través de dos generaciones, la del inmigrante que llega a Madrid y aquélla de los hijos que triunfan en los negocios a mediados del siglo XVII. La debilidad demográfica y la asimilación social que sufre el inmigrante francés no nos permite encontrar una continuidad en la tercera generación. De hecho, la historiografía económica y social sobre la burguesia mercantil ha constatado hace tiempo que son pocas las familias de comerciantes que superan las fatídicas barreras de las tres generaciones ${ }^{53}$. Nuestro propósito es examinar sólo a los miembros más significativos que conforman las dos generaciones que cubren los años centrales del siglo XVII hasta 1679.

Estos grupos familiares, que llegaron en la primera mitad del siglo XVII a Madrid, se instalan en un entorno diferenciado, el de la calle de las Postas, calle Mayor y Portales de Santa Cruz aunque para desplazarse luego al entorno del barrio de las lonjas -el de la calle Preciados, del Carmen y calle de San Jerónimo, además del más distanciado de la Red de San Luis-, pasando por el foco de la Puerta del Sol y calle de la Zarza. En este sentido, la cuestión que adquiere más importancia es la creación de un complejo entramado de apoyos mutuos de carácter horizontal tan necesarios dada su condición de extranjeros y la debilidad demográfica de sus familias. Además, son las circunstancias sociales y culturales las que moldean la estructura del grupo doméstico y es necesario, por tanto, conocer las condiciones de formación de una estructura familiar en función

52. A.H.P.M., P. 7248 , fols. 32-33v. Entre ellos taberneros de corte como Juan de Heredia y otros familiares, como su suegra, Isabel de Gamarra y Ana de Espinosa, de quien desconocemos su "status" socioprofesional y relación social.

53 MOLAS, P., La burguesia mercantil.., pág. 29 y 31. 
del contexto social, por supuesto, sin olvidar el papel del mercado como matizador de los sistemas de transmisión. En líneas generales, podemos decir que mantienen una acentuada endogamia dentro del grupo nacional, con unas características socioeconómicas muy definidas. Ahora el trato económico de los franceses se homologa al de la burguesía mercantil madrileña y el nuevo sesgo que el parentesco adopta entre estas familias permite que se diluya su contenido nacional.

\section{Los Broquel una familia francesa a estudio}

Las noticias en torno a los Broquel y su asentamiento en Madrid se remontan, a la primera mitad del siglo XVII. A principios de la década de 1630 Juan Broquel "el mayor" un recién llegado, joven y soltero buscaba la rápida inserción social por vía matrimonial. En 1634 se casa con Magdalena Marcha, hija de un ropero francés instalado en Madrid desde principios de siglo. De Juan Broquel "el mayor» tenemos escasa información salvo que tiene intereses en el negocio de joyería hasta 1650. Su esposa Magdalena, tras enviudar quedaba a cargo de la tienda del matrimonio en los aledaños de la calle Mayor, en un modesto establecimiento alquilado a algun propietario madrileño. En 1662 repitió matrimonio en Madrid, esta vez con Francisco Dupuy, otro mercader francés, de profesión "caxero" ${ }^{54}$ en promoción ${ }^{55}$, que se desarrolla en los ambientes comerciales y sociales de donde procede la esposa, en un entorno con un alto contenido nacional que se abre a la sociedad madrileña en un proceso de integración permitiendo que se diluya su contenido nacional.

En efecto, la familia de Magdalena afianza su capital familiar en el comercio de ropa usada. María Marcha, su hermana, se había casado con Juan Chalvet, otro ropero de viejo francés, y la hija del matrimonio, Sebastiana Chalvet contraerá a su vez nupcias con Antonio Julian un veterano ropero cuya familia había sido represaliada en $1635^{56}$. Los círculos mercantiles de la lonja de Magdalena se mantuvieron, por tanto, en el

\footnotetext{
54 Así se denomina a los mercaderes ambulantes franceses.

55 Un caso estudiado es el de Juan Palanca: CARBAJO ISLA, M. F., “El patrimonio de un panadero del siglo XVII", Economía y sociedad en la España moderna y contemporánea, GoMEZ MENDOZA, (Ed.) Madrid, 1996, pág. 35. Cuya dote aportada en el segundo matrimonio con Teresa López ascendió a 60.000 reales unos 2.040 .000 maravedies, es decir, el valor de dos casas en la calle de Toledo.

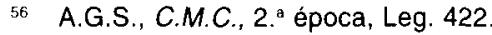


entorno de la colonia francesa estructurada por roperos de viejo y cajeros que se organizan en torno a la cofradía de San Luis de los Franceses. Poco sabemos sobre el proceso de asentamiento familiar y comercial de estos dos matrimonios franceses. No obstante, las relaciones de los Broquel-Marcha en Madrid son numerosas pero se encuentran delimitadas a un entorno socioprofesional: el de los roperos de viejo y caxeros franceses con los que comparten procedencia común y a los que abastecen. Recordemos que mantenía la familia una relación muy directa con Juan Texandier, cajero de profesión, miembro de una familia de roperos de viejo de la calle de la Sal, la de Guillermo Texandier ${ }^{57}$. Jacques Sauret era otro de los mercaderes cajeros que se abastecían en la tienda de joyería de los Broquel-Marcha. Una clientela que con modestos capitales vertebraba este matrimonio en un entorno socioprofesional muy determinado: el de la venta ambulante y la ropería de viejo.

Por todo ello, estos golpes de suerte y de fortuna impidieron, en ocasiones, a esa generación de mercaderes perpetuar el capital en el ramo de la joyería e invertirlo en el comercio internacional. En este sentido, este matrimonio de mercaderes es uno de nuestros primeros ejemplos de que pese a su carácter foráneo se instala como grupo extranjero en espera de mejores oportunidades, por lo menos hasta que se produzca el cambio de siglo. Por su parte Magdalena, tras su segundo matrimonio con Dupuy en 1662 alquilaba su local —una alcoba con derecho a cocina - a Antonio Cocot, un ropero de viejo francés, por un período de tres años ${ }^{58}$. La segunda generación de esta familia, la de los hijos del matrimonio BroquelMarcha del que habian nacido: Magdalena de Jesús que ingresaría en el convento de las Maravillas de Madrid con una dote de dos mil ducados, una cantidad que había heredado de su tía María Marcha viuda de Sebastián Chalbet, otro ropero de viejo francés ${ }^{59}$, y Juan Broquel el "menor"

\footnotetext{
57 Tal es el caso de este mercader caxero francés establecido en Madrid en 1620 en el barrio de San Luis de la Corte, tres décadas después regentaba una modesta tienda de ropa usada junto a otros mercaderes de ropa de la calle de la Sal: A.H.P.M., P. ${ }^{\circ} 7248$, fols. $281-281$ v., 29 de octubre de 16.59. Localizado asimismo por ALCOUFFE, D., "Contributión a la connaissance...", pág. 196; Dominguez Ortiz, A., Los extranjeros en la vida española..., (1. ${ }^{a}$ ed. 1960), Madrid, 1997, pág. 76.

58 A.H.P.M., P. ${ }^{\circ} 7250$, fols. $83-83 v$. El alquiler de un local modesto podía ascender a 200 reales siempre pagados por adelantado. Era una vivienda para puesto de ropería en casa de don Diego Antonio de Ulloa Manrique que se encontraba junto a una zapatería de viejo. Esta vivienda en subarriendo habia sido alquilada por Magdalena el 1 de noviembre de 1659 por un período estipulado en contrato de seis años.

59 A.H.P.M., P. ${ }^{\circ} 9765$, fol. 343-343v. "Poder y licencia otorgada por Francisco Dupuy a su mujer Magdalena Marcha para abonar la dote de Magdalena de Jesús en su ingreso en el Convento de las Maravillas de Madrid".
} 
que se mantiene en estos niveles socioprofesionales de los roperos de viejo, descartando la aventura del comercio internacional pues este seguiría los pasos de la familia materna estableciéndose en Madrid como ropero de viejo.

A principios de 1658 Juan Broquel "el menor» recíbía de su madre Magdalena dos mil ducados de vellón, un capital que le permitiría independizarse de la economía familiar y que procedía de la herencia de su padre difunto. Ahora, un buen matrimonio con la hija de un conocido mercader del comercio minorista que, por una parte, consolidara la posición social de la familia en el comercio madrileño y, por otra, supusiera por parte de la familia de la nuera, además, la incorporación de un yerno a la familia que permitiría la continuación del negocio ahora en el ramo de los tejidos y en una zona comercial preferente en pleno corazón de la corte, aunque en modestos locales. El hijo del matrimonio Juan Broquel «el menor" se casó con María Moreno, hija de unos vecinos de la localidad madrileña de Ciempozuelos — 'hinterland' local de la corte- y viuda de un comerciante de Madrid, instalándose el matrimonio en la Corte regentando una ropería de viejo, volviendo a los orígenes comerciales del negocio familiar. Este capital inicial le permitía establecerse como ropero de viejo en Madrid, una circunstancia que no debía producirse entre los roperos más modestos que contaban con una hacienda escasa que no ascendía a más de 5.000 reales de vellón. El capital se incrementa cuando recibe los dos mil ducados por la legítima del padre fallecido y decide establecerse por su cuenta. No cabe duda, el matrimonio con María Moreno, cuya dote ya conocemos incrementaría su capital medio e impulsaría su negocio ${ }^{60}$. Junto a su marido regenta el negocio hasta 1663 año en que fallece Juan Broquel, «el menor» ${ }^{61}$. Esta nueva situación con la experiencia adquirida en el negocio familiar y la tradición mercantil de la saga a la que pertenecía -la de los roperos de viejo, pues el padre joyero había fallecido demasiado pronto, permitiría al joven Broquel retomar

60 En ropas el valor ascendia a 12.322 reales; 16.000 reałes en arrendamiento y traspaso de la tienda familiar; y 6.000 reaies de vellón en dinero en efectivo. Es decir que la empresa de Broquel hijo se compone de mercancias (ropas y vestidos), un local comercial arrendado y dinero. Un buen comienzo. Posiblemente la tienda traspasada fuera de su abuelo, pues es Magdalena Marcha la que hizo el traspaso al otorgante por tres años. Asimismo le entrega el dinero en efectivo para completar la cantidad de 2.000 ducados de vellón que era su hijuela del inventario pues es la misma cantidad la que se entrega a Magdalena de Jesús aunque en esta ocasión se recurra a la hermana de Magdalena, María Marcha para poder entregar dicha cantidad, lo que indicaba la poca solvencia de la familia Marcha-Dupuy en este periodo.

61 A.H.P.M., P. 10.392 , fols. 955-957, testamento de Juan Broquel y su inventario en fols. 958-1029, 17 de agosto de 1663. Ver Heanandez, M., A la sombra de la Corona..., pág. 346. Apendice 3.1 . 
el negocio familiar de la ropería pero afianzando su capital mercantil María llevaba al segundo matrimonio una hacienda tasada en 7.835 reales de vellón ${ }^{62}$ pues era la viuda de Francisco Carlos Chabrias -el hijo difunto del lencero Guillermo Chabrias ${ }^{63}$ que se habia establecido en Madrid en la década de los treinta después de haber practicado durante toda vida la venta ambulante de mercancías de lencería-. Esta situación permite a esta pareja de mercaderes roperos mantener no sólo una relación fluida con el gremio de roperos también con el de lenceros matriculados como el matrimonio de Juan López y doña Bernarda de Villar ${ }^{64}$.

Finalmente, el 24 de marzo de 1674 María Moreno, viuda de Juan Broquel «el menor» poseía una vivienda de mercader acomodado y por esas fechas gestionaba la hacienda familiar que consistía en unas casas principales en pleno barrio francés que arrienda a Bartolomé Simón, guantero y vecino de la villa de Madrid en nombre de sus dos hijos menores de edad, por 3.150 reales anualmente, cobrándose cada medio año lo correspondiente por adelantado. El 13 de septiembre de 1673 la herencia que había legado Magdalena Marcha a sus nietos - la tercera generación-, Juan y Antonia, hijos de Juan Broquel «el menor» y María Moreno, correspondía a las casas "principales" que habian pertenecido a la familia y que se encontraban en la calle que sube de la Puerta del Sol a la red de San Luis ${ }^{65}$.

\section{Los Baraduque}

Dentro del grupo auvergnesse destaca, por último, otra familia, los Baraduque, ligados por vínculos familiares al negocio de la joyería de Madrid. Las noticias en torno a este grupo familiar y su asentamiento en

\footnotetext{
62 Unos 266.390 maravedies:A.H.P.M. P. ${ }^{\circ} 7245,7$ de octubre de 1656 , carta de pago. Por otra parte, el sistema de herencia castellano preveía la mitad de los bienes gananciales para la viuda. Si a ello añadimos la recuperación de la dote en el momento de la participación de bienes del marido y que, en ocasiones, éste deja a la esposa el quinto de libre disposición, comprenderemos que los pocos recursos disponibles, sin ingresos que equilibran el presupuesto familiar, asi como el acceso paulatino de los hijos al matrimonio pueden ir deteriorando su situación económica de las generaciones siguientes que no pueden mantener el ascenso conseguido por sus predecesores: ChaCON, FCo., La familia en España (...) ..., pág. 32.

${ }^{63}$ Unos niveles de riqueza: A.H.P.M., P. ${ }^{\circ} 7140$, fols. 789 , Inventario de la mujer de Guilllermo Chabrias.

64 A.H.P.M., P. 7140 , fols. 288-289v, habian sido nombrados tutores de los hijos el matrimonio en caso de que falleciera el "pater familias".

65 A.H.P.M., P. 9230 , fols. 176-176v, 24 de marzo de 1673, arrendamiento de unas casas principales a Bartolomé Simón, un guantero avecindado en Madrid por un valor de tres mil ciento cincuenta reales de vellón anuales, abonándose cada medio año por adelantado.
} 
Madrid aporta los primeros datos sobre el "cursus honorum" del mercader de joyería francés que con el tiempo transforma su negocio en una tienda de «Ionja abierta». En efecto, la necesidad de adaptación exige una rápida integración en la sociedad madrileña. La promoción social de estos comerciantes galos no implicaba casi nunca una ruptura con el medio social al que pertenecia. La mejora social y económica de Pedro Baraduque, "pater familias" de la casa de comercio en Madrid en la década de los cincuenta, fue gracias a su introducción como factor asociado de una joyería ya arraigada, la que regentaba Jusepe Salazar donde habia entrado a trabajar como mancebo, unos años antes. Pedro Baraduque es oriundo de la villa de Lastor, en el obispado de Clermont (Basse Auvergne) y era hijo de Pedro Baraduque, que había ya fallecido en su villa natal y de Francisca Redonchal, que vivía allí en 1650. Su adscripción al Hospital y Cofradía le sitúa en el mismo nivel de integración que los Broquel pero plenamente identificado con la burguesía mercantil madrileña constituyendo un buen ejemplo de la acumulación de capital realizado. Ahora surge la necesidad de buscar nuevas solidaridades y amistades entre la burguesía mercantil madrileña especializada en el comercio al detalle de su mismo ramo de la comercialización.

Analizamos, por tanto, el "cursus honorum" del afortunado mancebo de joyería. Sus orígenes modestos eran indudables, pero el matrimonio con Ana María Salazar, hija de Jusepe de Salazar y viuda del mercader madrileño Juan de Orozco - se repetían las estrategias de ascenso realmente importante de los Broquel de la segunda generación-, un matrimonio que definitivamente le permitía homologarse aún más con la burguesía mercantil madrileña. Por otra parte, los parientes de este mercader constituyen un complejo entramado de apoyos mutuos ya que su familia se repartía entre las ciudades castellanas del 'hinterland' regional de Madrid, en particular por las villas de Guadalajara, como Pastrana, donde reside su hermana Ana Baraduque, casada con Pedro Manuel, posiblemente de origen francés, y que figura, junto con Clemente Clemente, un mercader de lonja lorenés, el 22 de abril de 1650 con motivo de su partida a la ciudad de Pamplona. Además, la firma familiar dispone de parientes fuera de la peninsula, concretamente en la ciudad de Clermont donde vive su hermana Micaela Baraduque, casada, a su vez, con un mercader apellidado Bisier y a la que lega en su testamento doscientos ducados de plata ${ }^{66}$.

66 A.H.P.M., P. ${ }^{\circ} 9152$, fols. 22 de abril de 1650 , fols. $109-114$ v. 


\section{CONSIDERACIONES FINALES}

Llegados al final de este paseo por las familias mercantiles francesas de la ropa y los tejidos concluimos que, por una parte, la familia del comerciante francés es la institución a través de la cual se lleva a cabo no sólo la reproducción de todo su sistema social, sino también la posibilidad de reproducción económica que el carácter endogámico de sus matrimonios realizados dentro del grupo nacional refuerza; por otra, las relaciones de parentesco, la constitución de alianzas matrimoniales y sobre todo un espacio aglutinador, la "casa", definidor de la unidad familiar y sobre todo de su realidad sociológica dirigida por el "pater familias" son algunos de los factores que condicionan y a su vez se ven condicionados por las directrices de este último.

Finalmente, la estructura de las relaciones sociales que hemos definido se mantiene en las década siguientes básicamente en el seno de la colonia francesa, a la par que algunas familias francesas desarrollan nuevas relaciones sociales en el seno de la sociedad madrileña. Este aspecto es básico para comprender una institución que atiende a la individualización pero que en sí misma crea una fuerza centrífuga que la comunica con la sociedad en la que se inserta ya en aquellos niveles comerciales dominados por los joyeros, lenceros y merceros franceses que constituyen la burguesia mercantil francesa en ascenso y que, en ocasiones, escalan hasta los peldaños del comercio internacional.

\section{APÉNDICE I}

Árboles genealógicos

Los Mateo

Maria Chacha $=$ Lucas Mateo $=$ Agueda Laurisecha

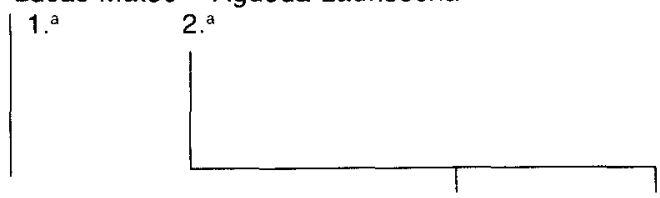

Antonio Mateo $=$ María Bosque de Miranda $=$ Giraldo Mateo Pedro Mateo 


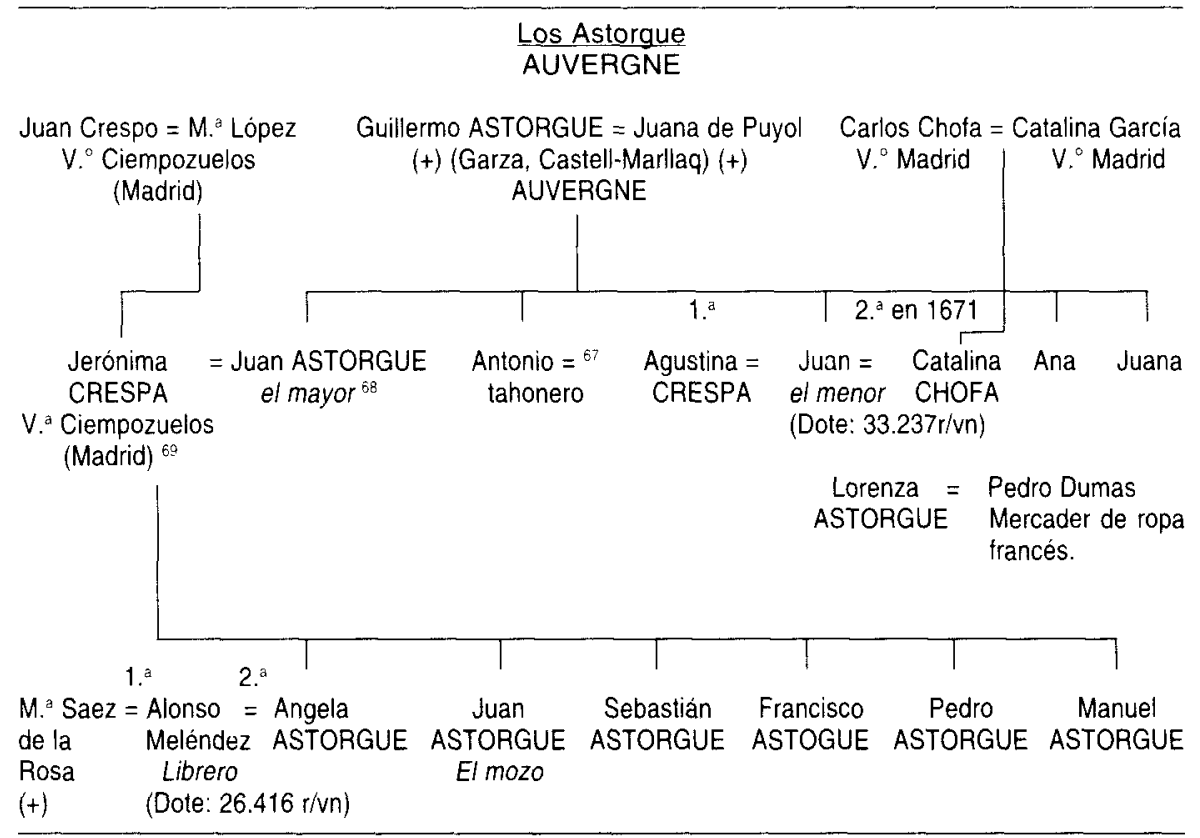

\section{Familia de la Fuente \\ Clermont, AUVERGNE}

Juan de la Fuente $=$ Juana Robert

Clermont

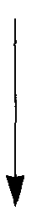

Pedro de la Fuente

Clermont

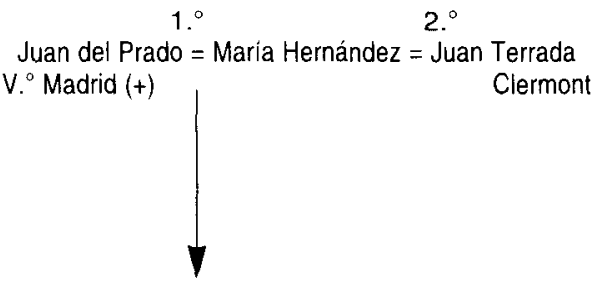

María del Prado (dote 2.641 rs y 174 mrs.)

67 Casado con francesa que reside en Francia.

58. Fue mayordomo de la Cofradía de San Luis sustituyendo en el cargo a Giraldo Mateo en 1659: A.H.P.M., P. ${ }^{\circ} 7249$, fols. 64 . El 16 de agosto de 1660 le sucedía en ese mismo cargo Juan Rigal, otro mercader de ropa usada francés: A.H.P.M., P. ${ }^{\circ} 7249$, fols. 363, carta de pago.

69 Hija de Juan Crespo y María López, vecinos de Ciempozuelos en la provincia de Madrid. 
Algunas sagas comerciales francesas en el Madrid de la segunda mitad...

\section{Familia Broquel - Marcha \\ AUVERGNE}

Fco. DUPUY ${ }^{70}=$ Magdalena Marcha $=$ Juan BROQUEL, el mayor

2. Mercadera

$(+), 13.9 .1673$

Mercader joyero

(+) 1649

María Marcha $=$ Juan Chalvet

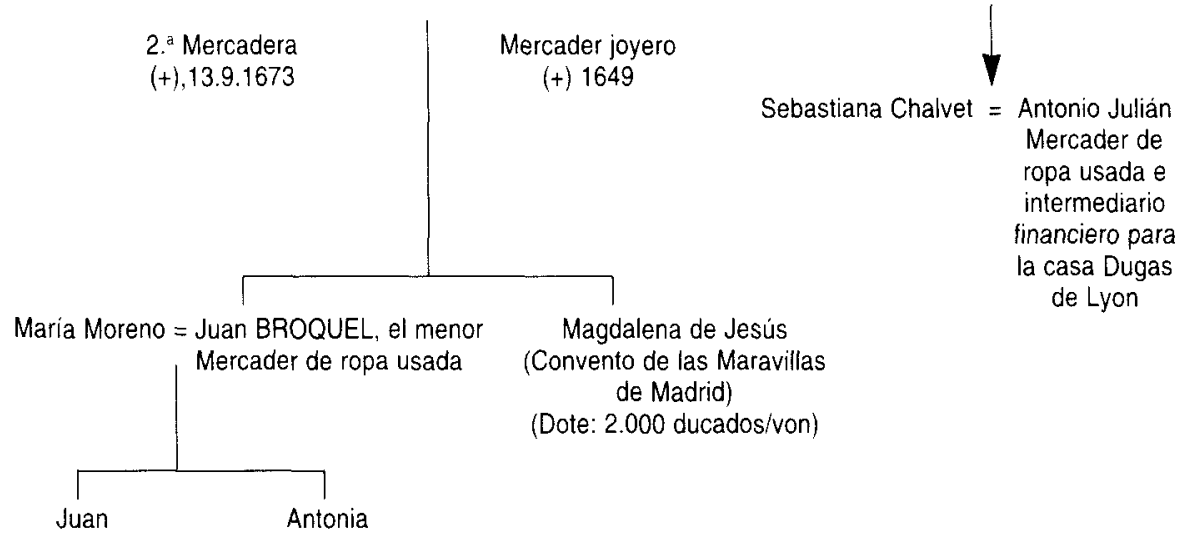

\section{Familia Baraduque}

AUVERGNE

$?=$ Jusepe de Salazar

Pedro Baraduque $=$ Francisca Redonchal

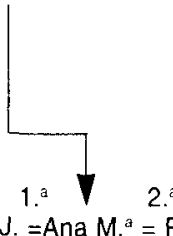

J. =Ana M. ${ }^{a}=$ Pedro BARADUQUE

Salazar Mercader de lonja

Vda

en Madrid

Ana Baraduque

Reside en la Villa

de Pastrana

(Guadalajara)

Pedro Manuel
Micaela $=F$. Bisier

Reside en

la Villa Clermont

(Francia)
Pedro Manuel

Villa Lastor

(Clermont)

70 A.H.P.M., P. ${ }^{\circ} 9765,19$ de mayo de i667, fols. $344-344 v$. y fols. $346-346 \mathrm{v}$. 


\section{APENNDICE /I}

Nómina de cofrades y mayordomos de la Cofradia del Espíritu Santo y Ntra. Sra. del Buen Fin, sita en el Hospital de San Luis de Francia de esta Corte . 24 de agosto de 1659.

\section{CARGOS DIRECTIVOS}

1. El licenciado don Claudio Charpi, administrador del dicho hospital.

2. Blas de la Torre, mayordomo mayor y tesorero mayor desde primero de agosto de 1659.

3. Guillermo Texandier, mayordomo de cera este año de 1659.

\section{DIPUTADOS (oficiales)}

4. Juan Astorgue, el mozo

5. Juan Constan, mayordomo mayor y de la cera que fueron en 1658

6. Giraldo Mateo

7. Simón de la Puente

8. Antonio Higuera

9. ${ }^{\circ}$ Fco Bes

10. Antonio del Prado, diputados

En $1662^{71}$ :

1. Pedro Robledo, administrador del dicho Hospital

2. Juan Rigal, diputado y mayordomo mayor que ha sido de ella

3. Agustín Crespo, mayordomo de cera

4. Antonio de Higueras, diputado

5. Juan de Astorgue, el mayor

6. Antonio Godet

7. Antoniodel Prado

8. Juan Astorgue el menor

9. Pedro de la Puente, el menor

En 1664 los oficiales y cofrades:

1. Pedro de Robledo

2. Juan astorgue, el menor;

3. Juan Braset, mayordomo de cera;

4. Pedro Botal

5. Juan Constan;

6. Juan Astorgue el mayor

7. Blas de la Torre,

8. Antonio de Higueras;
Resto de COFRADES

11. Juan Terrada

$12 .^{\circ}$ Giraldo Forastero

13. Juan Astorgue

$14 .^{\circ}$ Antonio Cocot

15. Antonio Blander

16. Agustín Crespo

17. Esteban la Puerta

18. Juan González

19. Cristóbal Tiulet

$10 .^{\circ}$ Giraldo Forastero

11. Jerónimo Forastero

$12 .^{\circ} \mathrm{Fco} \mathrm{Bez}$

13. Pedro Molinaq

14. Fco Trigoso

15. Esteban de la Puerta

16. Antonio de Baus

17. Lucas de la Torre

18. Juan Constan

19. Pedro Llornaque
9. Antonio del Prado

10. Antonio Bodete

11. Esteban de Lampre

12. Agustin Crespo

13. Antonio de Baus

14. ${ }^{\circ}$ Esteban de la Puerta

15. Pedro Merlín y

16. Antonio Mateo ${ }^{72}$.

71 A.H.P.M., P. ${ }^{\circ} 7250$, fols. 313-317v, 16 de agosto de 1662 . Carta de poder de los oficiales y cofrades de San Luis a Juan Astorgue "el mayor", "alquilador de vestidos", que ha sido nombrado tesorero y mayordomo mayor en 1662, desde el 1 de agosto hasta el 1 de agosto de 1663.

72 A.H.P.M., P. 7250 , fols. 478-79v. 25 de agosto de 1664 dan poder a Juan Astorgue "el menor". 
En 6 de diciembre de $1676^{3}$ :

\section{MAYORDOMOS}

Pedro Molinet

Ant. del Prado

Diego de Laboria

Guillermo Montero

Luis Porres y Bonifaz

Pedro Vicioso, mayordomo

Juan Manuel del Prado y Guillermo Fabre

* Elaboración propia

\section{COFRADES:}

Juan Chavano Pedro de Apuente

Guillermo Ventador Juan Bautista de Zalamea

Roque de Medina Francisco Bes

Pedro de Utel Gregorio Martínez

73 A.H.P.M., P. ${ }^{\circ} 10.430$, sin foliar, 6 de diciembre de 1676. Con ocasión de esta reunión de la cofradía se reunieron los cofrades y directivos del cuadro y el motivo era que dijeron que $\mathrm{D}$. Polonia Rojel, por una cláusula de su testamento cerrado que por su muerte se abrió y en 15 de agosto del año pasado de 1674 mandó a la dicha cofradía un censo de 1.000 ducados de principal y 50 de renta que le debía doña Maria de Chaves y de la Guilla. 